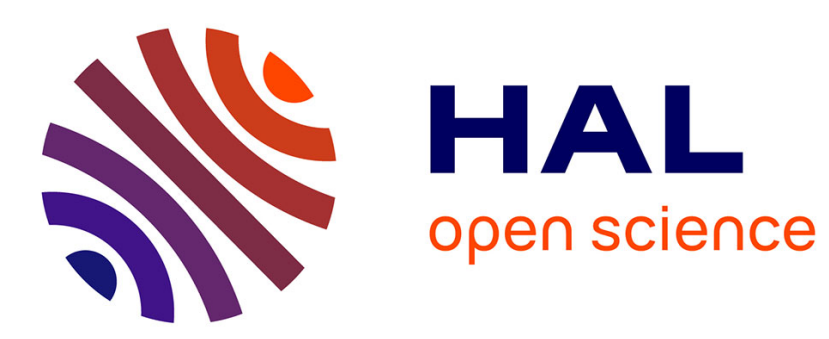

\title{
Shearing effects on the breathing mechanism of a cracked beam section in bi-axial flexure
}

Saber El Arem

\section{To cite this version:}

Saber El Arem. Shearing effects on the breathing mechanism of a cracked beam section in bi-axial flexure. European Journal of Mechanics - A/Solids, 2009, 28 (6), pp.1079-1087. hal-00408872

\section{HAL Id: hal-00408872 \\ https://hal.science/hal-00408872}

Submitted on 4 Aug 2009

HAL is a multi-disciplinary open access archive for the deposit and dissemination of scientific research documents, whether they are published or not. The documents may come from teaching and research institutions in France or abroad, or from public or private research centers.
L'archive ouverte pluridisciplinaire HAL, est destinée au dépôt et à la diffusion de documents scientifiques de niveau recherche, publiés ou non, émanant des établissements d'enseignement et de recherche français ou étrangers, des laboratoires publics ou privés. 


\title{
Shearing effects on the breathing mechanism of a cracked beam section in bi-axial flexure
}

\author{
Saber El Arem \\ Laboratoire Sols Solides Structures-Risques, Domaine Universitaire BP53 38041 \\ Grenoble, France
}

\begin{abstract}
The main purpose of this paper is to complete the works presented by Andrieux and Varé [2002] and El Arem et al. [2003] by taking into account the effects of shearing in the constitutive equations of a beam cracked section in bi-axial flexure. The paper describes the derivation of a lumped cracked beam model from the three-dimensional formulation of the general problem of elasticity with unilateral contact conditions on the crack lips. Properties of the potential energy and convex analysis are used to reduce the three-dimensional computations needed for the model identification, and to derive the final form of the elastic energy that determines the nonlinear constitutive equations of the cracked transverse section. We aim to establish a relation of behavior between the applied forces and the resulting displacements field vectors, which is compatible with the beams theory in order to allow the model exploitation for shafts dynamics analysis. The approach has been applied to the case of a cracked beam with a single crack covering the half of its circular cross section.
\end{abstract}

Key words: beam finite element, breathing crack, unilateral contact, shearing effects, convex analysis.

\section{Introduction: state of the art}

Since the early 1970s when investigations on the vibrational behavior of cracked rotors began, numerous papers on this subject have been published, as a literature survey by Dimarogonas [1996] shows. The analysis of the behavior of cracked rotating machinery shafts is a complex structural problem. It requires,

Email address: saber.el-arem@polytechnique.edu (Saber El Arem ).

$U R L$ : authors.elsevier.com/locate/latex (Saber El Arem ). 
for a relevant description, a fine and precise modeling of the shaft and cracks in order to allow the identification and calculation of the parameters characterizing their presence.

Researchers dealing with the problem of rotating cracked beams recognize its two main features, namely:

- the determination of the local flexibility of the beam cracked section;

- the consideration of the opening-closing phenomenon of the crack during the shaft rotation, commonly called breathing mechanism of the crack, and responsible of the system nonlinear behavior: when the shaft is rotating, then the crack opens and closes according to the stresses developped in the cracked surface. If these stresses are extensive, then the crack opens, resulting in a reduced shaft stiffness. When the stresses are compressive, then the crack remains closed and the shaft has the same stiffness as the non-cracked shaft. Thus, the system stiffness is depending on the cracked section position (Figure 1).

This breathing mechanism depends on the shaft rotation in the case when the static deflection dominates the vibration of the rotating shaft. This is a very common situation in large turbine-generators rotors.

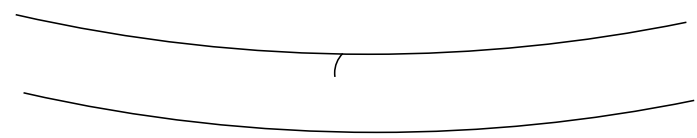

(a) crack in compressed zone

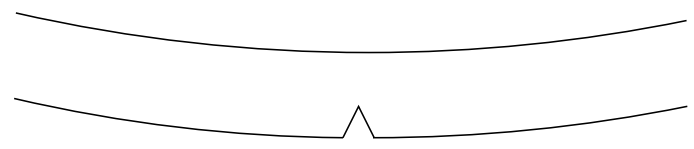

(b) Crack in tense zone

Fig. 1. Crack breathing mechanism

During the last three decades, great attention has been paid by several research scientists to the analysis and diagnosis of cracks in rotating machinery. The excellent review papers by Entwistle and Stone [1990], Dimarogonas [1996], Wauer [1990a] and Gasch [1993] cover many aspects of this area and summarize the most relevant analytical, experimental and numerical works conducted in the last three decades and related to the cracked structures modeling.

There have been different attempts to quantify local effect introduced by cracks. The analysis of the local flexibility of a cracked region of structural element was quantified in the 1950s by Irwin [1957a,b], Bueckner [1958], Westmann and Yang [1967] by relating it to the Stress Intensity Factors (SIF). Afterwards, the efforts to calculate the SIF for different cracked structures with simple geometry and loading was duplicated [Tada et al., 1973, Bui, 1978]. 
Most researchers agree with the application of the linear fracture mechanics theory to evaluate the local flexibility introduced by the crack [Gross and Srawley, 1965, Anifantis and Dimarogonas, 1983, Dimarogonas and Paipetis, 1983, Dimarogonas, 1996, Papadopoulos and Dimarogonas, 1987a,b,c, Papadopoulos, 2004]. Obviously, the first work was done in the early 1970s by Dimarogonas [1970, 1971] and Pafelias [1974] at the General Electric Company. The energy release rate approach combines the linear fracture mechanics to rotordynamics theory in order to calculate the compliance caused by a transverse surface crack affecting a rotating shaft. A good review on this method is presented by Papadopoulos [2008].

For an elastic structure, the additional displacement $\boldsymbol{u}$ due to the presence of a straight crack of depth $a$ under the generalized loading $\boldsymbol{P}$ is given by the Castigliano theorem

$$
\boldsymbol{u}=\frac{\partial}{\partial \boldsymbol{P}} \int_{0}^{a} \boldsymbol{G}(a) d a
$$

$\boldsymbol{G}$ is the energy release rate related to the SIF by the Irwin formula [Irwin, 1957a]. Then, the local flexibility matrix coefficients are obtained by

$$
c_{i j}=\frac{\partial^{2}}{\partial P_{i} \partial P_{j}} \int_{0}^{a} \boldsymbol{G}(a) d a, \quad 1 \leq i, j \leq 6
$$

Extra diagonal terms of this matrix are responsible for longitudinal and lateral vibrations coupling that could be with great interest when dealing with cracks detection.

In two technical notes of the NASA, Gross and Srawley [1964, 1965] computed the local flexibility corresponding to tension and bending including their coupling terms. This coupling effect was observed by Rice and Levy [1972] in their study of cracked elastic plates for stress analysis.

Dimarogonas and his co-workers [Dimarogonas, 1982, Dimarogonas and Paipetis, 1983, Dimarogonas, 1987, 1988], and Anifantis and Dimarogonas [1983] introduced the full $(6 \times 6)$ flexibility matrix of a cracked section. They noted the presence of extra diagonal terms which indicate the coupling between the longitudinal and lateral vibrations. Papadopoulos and Dimarogonas [1987a,b,c], and Ostachowicz and Krawwczuk [1992] computed all the $(6 \times 6)$ flexibility matrix of a Timoshenko beam cracked section for any loading case.

However, there are no results for the SIF for cracks on a cylindrical shaft. Thus, Dimarogonas and Paipetis [1983] have developed a procedure which is commonly used in FEM software: the shaft was considered as an assembly of elementary rectangular strips where approximation of the SIF using fracture mechanics results remains possible (Figure 2). The SIF are obtained by 


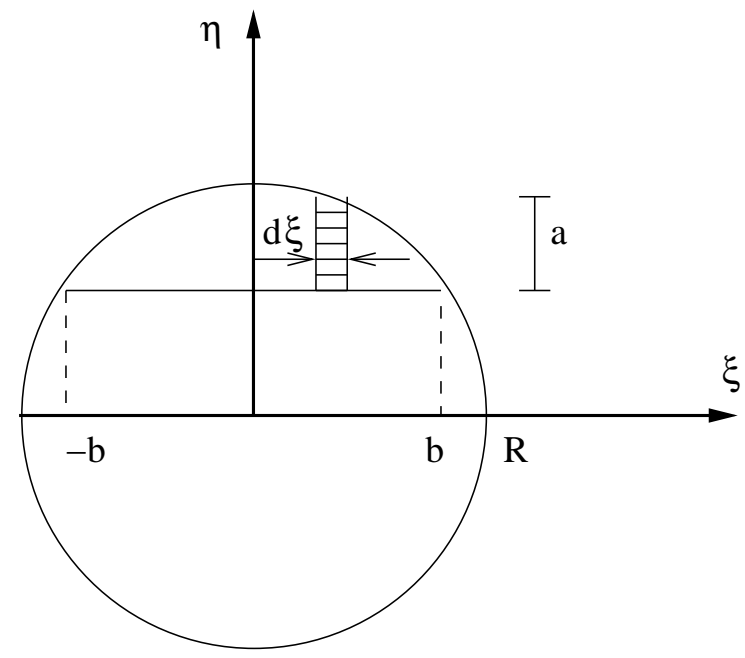

Fig. 2. Geometry of the shaft cracked section

integration of the energy release rate on the crack tip by

$$
c_{i j}=\frac{\partial^{2}}{\partial P_{i} \partial P_{j}} \int_{0}^{a} \int_{-b}^{b} \boldsymbol{G}(a, \xi) d \xi d a
$$

Although it offers the advantage of being easy to insert in a numerical algorithm, this method has some limitations. In fact, some numerical problems were reported by Abraham et al. [1994] when the depth of the crack $a$ exceeds the section radius $R$. Dimarogonas [1994], in his reply, stated that this divergence does not reflect reality; it is due to the assumption of a $2 \mathrm{D}$ stress distribution which is not valid near the ends of the crack tip.

Papadopoulos [2004] suggested to consider equation (3) with :

$$
0.90 b \leq|\xi| \leq 0.95 b
$$

when the crack depth $a$ exceeds the shaft radius $R$.

Wauer [1990b] explored the dynamics of a cracked, distributed parameter rotor component. The proposed model is a rotating Timoshenko shaft which is also flexible in extension and torsion. The stiffness matrix is constructed using the energy release rate approach as described in papers by Papadopoulos and Dimarogonas [1987a,b], and Gudmundson [1983]. The geometric discontinuity due to the crack is replaced by a load discontinuity. The procedure reduces the problem to equations for one uniform beam with a modified load distribution. The proposed approach is a powerful instrument to obtain approximate results by a relatively small calculation expense. Although the shearing is considered in this approach, the author did not discuss the importance of its effects on the crack breathing mechanism. 


\section{Review of the Andrieux and Varé model}

An original method for deriving a lumped model for a cracked beam section was proposed by Andrieux and Varé [2002]. Based on three-dimensional computations, the procedure incorporates more realistic behavior of the cracks than the previous models, namely the unilateral contact conditions on the crack lips and their breathing mechanism under variable loading. The method was derived from three-dimensional formulation of the general problem of elasticity with unilateral contact conditions on the crack lips. The authors established properties of the potential energy of this problem to reduce the amount of computation required for its determination in the case of a beam containing cracks of any shape and number. Convex analysis was also used to derive the final form of the energy that determines the nonlinear constitutive equations of the section of the beam which was incorporated in a FE analysis code. Great attention is paid to the capability of such a model to take into account the real 3D geometry of a crack and to represent, as general as possible, the effects of different load components on its nonlinear behavior.

The experimental validation of the approach is presented by Stoisser and Audebert [2008]. The authors reported that the model reproduces with good accuracy the overall behavior of the shaft line in presence of cracks. The experimental validation allows the use of the model, with confidence and reliability, for the determination of the dynamics of supposed cracked rotors.

Based on the approach of Andrieux and Varé [2002], El Arem and Maitournam [2008, 2007] presented a method of construction of a cracked beam finite element which they used afterwards for the stability analysis of cracked shafts. The authors distributed the additional energy due to the cracked section on the entire length of the cracked beam finite element. Considerable gain in computing efforts was reached compared to the nodal representation of the cracked section when dealing with the numerical integration of differential equations in structural dynamics.

The cracked structure of Figure 3(a) is subjected to an end moment $M_{2 L}=$ $\left(M_{x}(2 L), M_{y}(2 L)\right)$ at $z=2 L$. Andrieux [2000] has demonstrated certain properties of the problem elastic energy, $W^{*}$, leading to a considerable gain in the three-dimensional calculus required for the identification of the constitutive equations. In particular, for a linear elastic material, under the small displacements and small deformations assumptions, and in the absence of friction on the crack lips, the energy function could be written by distinguishing the contribution of the cracked section from that of the non-cracked elements, in the form :

$$
W^{*}\left(\boldsymbol{M}_{2 L}\right)=W^{*}(\boldsymbol{M})=W_{s}^{*}(\boldsymbol{M})+w^{*}(\boldsymbol{M})=\frac{L}{E I}\|\boldsymbol{M}\|^{2}(1+s(\Phi))
$$

where $\boldsymbol{M}=\left(M_{x}, M_{y}\right)$ is the resulting couple of flexural moments at the cracked section, $W_{s}^{*}$ the total elastic energy of non-cracked structure subjected 


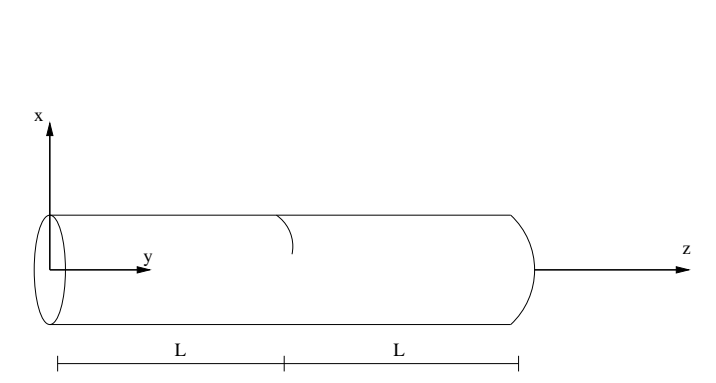

(a) Three-dimensional model

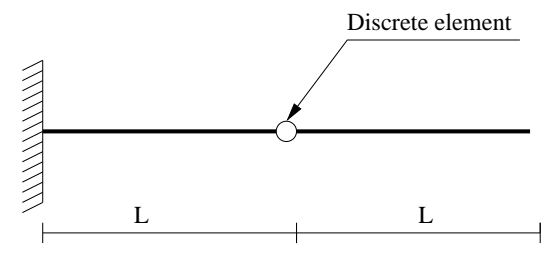

(c) One-dimensional model

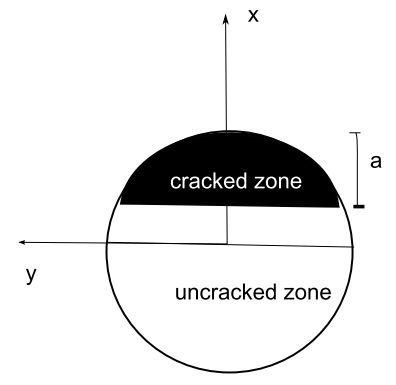

(b) Cracked transverse section

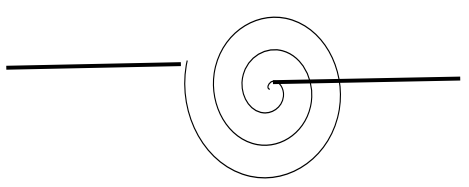

(d) Discrete element: nonlinear flexural spring

Fig. 3. The cracked beam model of Andrieux and Varé [2002]

to the flexural moment $\boldsymbol{M}$ and $w^{*}$ the additional elastic energy due to the presence of the cracked section. In order to simulate a rotating load on a fixed beam, the bending load is applied in several aperture angles $\Phi=\operatorname{atan}\left(\frac{M_{y}}{M_{x}}\right)$, with $\Phi$ varying over $[0,2 \pi[. E$ is the Young modulus and $I$ quadratic moment of inertia.

In this framework, the nonlinear constitutive equations of the discreet element modeling the cracked section are obtained by differentiating $w^{*}$ with respect to $\boldsymbol{M}$. We obtain

$$
[\boldsymbol{\theta}]=\left(\begin{array}{c}
{\left[\theta_{x}\right]} \\
{\left[\theta_{y}\right]}
\end{array}\right)=\frac{2 L}{E I}\left(\begin{array}{cc}
s(\Phi) & -\frac{1}{2} s^{\prime}(\Phi) \\
\frac{1}{2} s^{\prime}(\Phi) & s(\Phi)
\end{array}\right)\left(\begin{array}{c}
M_{x} \\
M_{y}
\end{array}\right) \text { with } s^{\prime}(\Phi)=\frac{d s(\Phi)}{d \Phi}
$$

However, for finite element computational codes in rotordynamics, a nonlinear relation of the form $[\boldsymbol{\theta}]=f(\boldsymbol{M})$ is to be identified. Thus, Andrieux and Varé [2002] introduced some properties of the additional deformation energy due to the cracked section, $w([\boldsymbol{\theta}])$. Thus, $w$ could be written as a quadratic function of the rotations jumps as:

$$
w\left(\left[\theta_{x}\right],\left[\theta_{y}\right]\right)=\frac{E I}{4 L} k(\varphi)\|[\boldsymbol{\theta}]\|^{2} \text { with } \varphi=\operatorname{atan}\left(\frac{\left[\theta_{y}\right]}{\left[\theta_{x}\right]}\right)
$$

The Légendre-Fenchel transform is used to establish the relation between the two energy functions $w^{*}$ and $w$, then the stiffness function $k$ is obtained from the compliance function $s$ identified from three-dimensional calculus.

As described by Andrieux and Varé [2002], the constitutive equations are finally obtained by differentiating $w$ with respect to $[\theta]$ as 


$$
\left(\begin{array}{l}
M_{x} \\
M_{y}
\end{array}\right)=\frac{E I}{2 L}\left(\begin{array}{cc}
k(\varphi) & -\frac{1}{2} k^{\prime}(\varphi) \\
\frac{1}{2} k^{\prime}(\varphi) & k(\varphi)
\end{array}\right)\left(\begin{array}{c}
{\left[\theta_{x}\right]} \\
{\left[\theta_{y}\right]}
\end{array}\right) \text { with } k^{\prime}(\varphi)=\frac{d k(\varphi)}{d \varphi}
$$

The purpose of this paper is to complete the models suggested by Andrieux and Varé [2002] and El Arem et al. [2003] by considering the shearing effects in the constitutive equations of a cracked beam section in bi-axial flexure. Our main purpose is to establish constitutive relations (nonlinear) between the applied forces and the resulting displacements field, which is compatible with the beams theory in order to allow the model exploitation for shafts dynamics analysis using a beam model.

\section{Description of the current model}

The study of the in-plane flexural behavior of a cracked beam by El Arem et al. [2003] and El Arem [2006] showed that for straight line tip cracks the shearing and flexure effects could be separated when aiming to identify the constitutive equations of a cracked transverse section. In fact, the bending moments are only responsible for the rotations discontinuities, and the shear forces for the displacements discontinuities (slips). In this paper, we present the case of the bi-axial flexural behavior.

Our objective is to identify the characteristics of a one-dimensional model (Figure 3(c) ) from accurate three-dimensional FE model (Figure 3(a)). The transverse cracked section (Figure 3(b)) is replaced by two lumped nonlinear flexural and shearing springs (Figure 3(d)) for which we aim to establish the constitutive equations.

The three-dimensional FE model considered is that of a cylinder of axis (oz), diameter $D=1 \mathrm{~m}$, cross section $S$, length $2 L=4 D$, containing, at midspan, a cracked section, cf. Figure 4 . The structural element, clamped at its end $z=0$, is subjected at $z=2 L$ to a couple of shear forces and a couple of flexural moments: $\left(T_{x}(2 L), T_{y}(2 L), M_{x}(2 L), M_{y}(2 L)\right)$.

In the one-dimensional (beam) model, the non-cracked parts of the structures are represented by Timoshenko beam elements, and the cracked section by a nodal element (zero length) allowing discontinuities of displacements and rotations. Indeed, this nodal element is composed of two uncoupled nonlinear springs modeling the cracked section flexural and shearing stiffnesses, cf. Figure 4 . The unilateral contact between the crack lips is considered.

The following assumptions are considered for the modeling of the structure: 


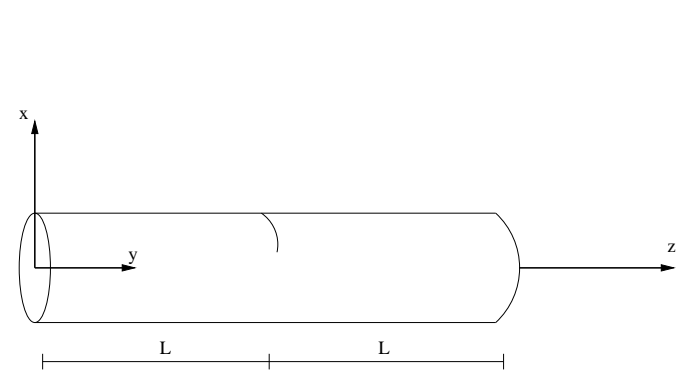

(a) Three-dimensional model

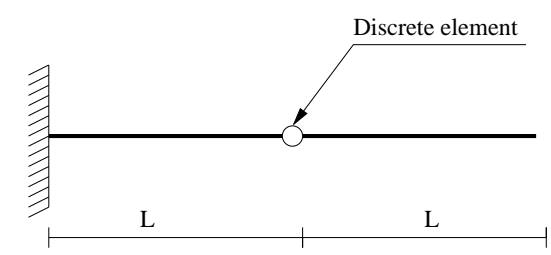

(c) One-dimensional model

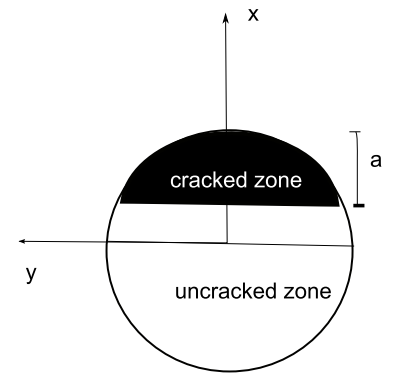

(b) Cracked transverse section

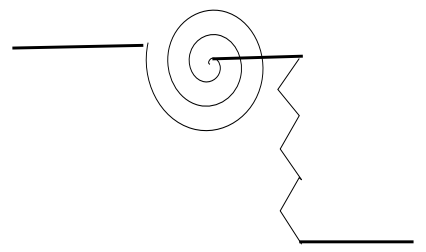

(d) Discrete element: two uncoupled springs

Fig. 4. The current cracked beam modeling

- assumption of small displacements and small deformations,

- linear and isotropic elastic material,

- transverse cracks of any shape and in any number,

- unilateral contact without friction between the crack lips,

- the crack is completely closed in the unstressed configuration.

\subsection{Properties of the energies functions of the problem}

Let $W^{*}$ be the total elastic energy of the system. According to what precedes, $W^{*}$ can be put in the form

$$
W^{*}(\boldsymbol{F})=W_{s}^{*}(\boldsymbol{F})+w^{*}(\boldsymbol{F})=W_{s}^{*}(\boldsymbol{F})+w_{f}^{*}(\boldsymbol{F})+w_{c}^{*}(\boldsymbol{F})
$$

where $W_{s}^{*}$ denotes the total elastic energy of the non-cracked structure under the loading $\boldsymbol{F}(2 L)$, and $w^{*}(\boldsymbol{F})$ the elastic energy due to the presence of the crack. The study of the in-plane flexural behavior showed that the bending and shearing effects can be dissociated. Based on this result, $w^{*}$ is divided into:

- $w_{f}^{*}(\boldsymbol{F})=w_{f}^{*}(\boldsymbol{M})$ denotes the part of $w^{*}(\boldsymbol{F})$ due to the resulting couple of flexural moments $\boldsymbol{M}=\left(M_{x}(L), M_{y}(L)\right)$ at the cracked section, and

- $w_{c}^{*}(\boldsymbol{F})=w_{c}^{*}(\boldsymbol{T})$ the part due to the couple of shear forces $\boldsymbol{T}=\left(T_{x}(L), T_{y}(L)\right)$.

According to Andrieux and Varé [2002], El Arem et al. [2003] and El Arem [2006], $w^{*}$ is strictly convex and positively homogeneous of degree 2 , 
from which rise the following properties:

Property 1 Functions $w_{c}^{*}$ and $w_{f}^{*}$ are strictly convex.

Property 2 Functions $w_{c}^{*}$ and $w_{f}^{*}$ are positively homogeneous of degree 2:

$$
\forall \lambda \geq 0 \text { we have }:\left\{\begin{array}{l}
w_{f}^{*}(\lambda \boldsymbol{M})=\lambda^{2} w_{f}^{*}(\boldsymbol{M}) \\
w_{c}^{*}(\lambda \boldsymbol{T})=\lambda^{2} w_{c}^{*}(\boldsymbol{T})
\end{array}\right.
$$

It should be noticed that an essential hypothesis for obtaining properties 1 and 2 is that the gap between the lips of the crack is zero in the unstressed configuration. For the contribution of the bending moments, the quadratic form of $w_{f}^{*}$ used in the study presented by Andrieux and Varé [2002], is considered:

$$
w_{f}^{*}(\boldsymbol{M})=\frac{L}{E I}\|\boldsymbol{M}\|^{2} s(\Phi)
$$

With $\Phi=\operatorname{atan}\left(\frac{M_{y}(L)}{M_{x}(L)}\right)$ and $s(\Phi)$ the additional flexibility due to the presence of the crack and related to the effects of flexural moments at the cracked section of the beam. Energy due to the shearing effects at the cracked section is also quadratic and can be put in the form:

$$
w_{c}^{*}(\boldsymbol{T})=\frac{L}{\mu \kappa S}\|\boldsymbol{T}\|^{2} s_{c}\left(\Phi_{c}\right), \text { with } \Phi_{c}=\operatorname{atan}\left(\frac{T_{y}(L)}{T_{x}(L)}\right)
$$

$\mu$ is the shear modulus and $\kappa$ the shear correction factor of Timoshenko. Due to property 2 , the problem of identification of the function $w_{c}^{*}$ on $\mathbb{R}^{2}$ is reduced to the identification of the flexibility function $s_{c}\left(\Phi_{c}\right)$ on the interval $[0,2 \pi]$ by considering the particular case of $\|\boldsymbol{T}\|=1$. This additional flexibility is identified from three-dimensional finite element calculus using Code_Aster ${ }^{\circledR}$.

Varé and Andrieux [2005] presented a simpler form of $w_{c}^{*}$. They brought the problem back, for certain shapes of cracks, to the identification of three constants by writing:

$$
w_{c}^{*}(\boldsymbol{T})=\frac{1}{2} T_{x}^{2}(L) s_{x}+\frac{1}{2} T_{y}^{2}(L) s_{y}+s_{x y} T_{x}(L) T_{y}(L)
$$

$s_{x}, s_{y}$ and $s_{x y}$ depend only on the geometry of the crack, they are independent of the parameters of loading and identified using the three following threedimensional finite element calculations cases:

$$
w_{c}^{*}\left(T_{x}=1, T_{y}=0\right), w_{c}^{*}\left(T_{x}=0, T_{y}=1\right) \text { and } w_{c}^{*}\left(T_{x}=1, T_{y}=1\right)
$$


This model allowed the obtaining, for certain cracks geometries, of results in excellent agreement with the three-dimensional FE calculations. However, it cannot be applied to any geometry of crack affecting beams or shafts with various cross section forms. Indeed, the shearing forces at the cracked section lead to the opening and closure of the crack according to mode II and/or mode III (modes of fracture). This depends on the orientation of the shearing force defined here by angle $\Phi_{c}$. The contact area between the lips of the crack, and consequently the additional flexibility due to its presence, depends on the direction of the applied shear force.

The present method, based on energy properties, could, without the use of additional simplifying assumptions, be applied to cracks of any shape and number affecting the same beam transverse section.

\subsection{Constitutive equations of the discrete element with shearing effects con- sideration}

The required relation describing the nodal element (Figure $4(\mathrm{~d})$ ) behavior is of the form:

$$
\left\{\begin{array}{l}
\boldsymbol{T} \\
\boldsymbol{M}
\end{array}\right\}=f\left(\left\{\begin{array}{l}
{[\boldsymbol{u}]} \\
{[\boldsymbol{\theta}]}
\end{array}\right\}\right)
$$

with

$$
[\boldsymbol{u}]=\left\{\begin{array}{l}
{\left[u_{x}\right]} \\
{\left[u_{y}\right]}
\end{array}\right\}=\left\{\begin{array}{l}
u_{x}\left(L^{+}\right)-u_{x}\left(L^{-}\right) \\
u_{y}\left(L^{+}\right)-u_{y}\left(L^{-}\right)
\end{array}\right\}
$$

and

$$
[\boldsymbol{\theta}]=\left\{\begin{array}{l}
{\left[\theta_{x}\right]} \\
{\left[\theta_{y}\right]}
\end{array}\right\}=\left\{\begin{array}{l}
\theta_{x}\left(L^{+}\right)-\theta_{x}\left(L^{-}\right) \\
\theta_{y}\left(L^{+}\right)-\theta_{y}\left(L^{-}\right)
\end{array}\right\}
$$

Consequently, it is the stiffness matrix of the nodal element which would be necessary to identify. Thus, we need to exploit the properties of the additional elastic deformation energy $w$ due to the presence of the cracked section for the displacements discontinuities $[\boldsymbol{u}]$ and the rotations discontinuities $[\boldsymbol{\theta}]$.

Given the assumption of separating the shearing and flexure effects at the cracked section, $w$ could be written in the form:

$$
w([\boldsymbol{u}],[\boldsymbol{\theta}])=w_{f}([\boldsymbol{\theta}])+w_{c}([\boldsymbol{u}])
$$

$w_{f}$ and $w_{c}$ are the elastic deformation energies associated with flexure and shearing, respectively. According to the work by Andrieux and Varé [2002] and El Arem [2006], $w_{f}$ and $w_{c}$ have the following properties: 
Property 3 Functions $w_{c}$ and $w_{f}$ are strictly convex.

Property 4 Functions $w_{c}$ and $w_{f}$ are positively homogeneous of degree 2:

$$
\forall \lambda \geq 0 \text { we have }:\left\{\begin{array}{l}
w_{f}(\lambda[\theta])=\lambda^{2} w_{f}(\lambda[\theta]) \\
w_{c}(\lambda[\boldsymbol{u}])=\lambda^{2} w_{c}([\boldsymbol{u}])
\end{array}\right.
$$

For $w_{f}$, the form proposed by Andrieux and Varé [2002] is considered:

$$
w\left(\left[\theta_{x}\right],\left[\theta_{y}\right]\right)=\frac{E I}{4 L} k(\varphi)\|[\boldsymbol{\theta}]\|^{2}
$$

With $\varphi=\operatorname{atan}\left(\frac{\left[\theta_{y}\right]}{\left[\theta_{x}\right]}\right)$ and $k$ the flexural stiffness function of the nodal element. Function $k$ is deduced from $s$ by using the Légendre-Fenchel transform relating $w_{f}$ to $w_{f}^{*}$.

Following the development steps described in (Andrieux and Varé [2002],Varé [2000]) for $w_{f}, w_{c}$ can be put in the form :

$$
w_{c}([\boldsymbol{u}])=\frac{\mu \kappa S}{4 L}\|[\boldsymbol{u}]\|^{2} k_{c}\left(\varphi_{c}\right)
$$

With $\varphi_{c}=\operatorname{atan}\left(\frac{\left[u_{y}\right]}{\left[u_{x}\right]}\right)$ and $k_{c}$ the shearing stiffness function of the nodal element to be identified. Using the Légendre-Fenchel transform we establish the relation between $w_{c}$ to $w_{c}^{*}$ by writing:

$$
\begin{aligned}
w_{c}([\boldsymbol{u}]) & =\sup _{\boldsymbol{T}}\left(\boldsymbol{T} \cdot[\boldsymbol{u}]-w_{c}^{*}(\boldsymbol{T})\right)=\sup _{\substack{\|\boldsymbol{T}\|=1 \\
\lambda \geq 0}}\left(\lambda \boldsymbol{T} \cdot[\boldsymbol{u}]-w_{c}^{*}(\lambda \boldsymbol{T})\right) \\
& =\sup _{\substack{\|\boldsymbol{T}\|=1 \\
\lambda \geq 0}}\left(\lambda \boldsymbol{T} \cdot[\boldsymbol{u}]-\lambda^{2} \frac{L}{\mu \kappa S}\|\boldsymbol{T}\|^{2} s_{c}\left(\Phi_{c}\right)\right)
\end{aligned}
$$

Contrary to the flexural flexibility function $s$ of the nodal element which vanishes for certain couples of flexural moments leading to a total closing of the crack, the linearity noted with respect to the shearing action shows that the flexibility function $s_{c}$ due to shearing is never zero:

$$
\forall \boldsymbol{T} \neq \mathbf{0} \text {, we have }[\boldsymbol{u}] \neq \mathbf{0}
$$

Thus, the required maximum in (18) is reached when:

$$
\lambda= \begin{cases}\frac{\mu \kappa S}{2 L} \frac{\boldsymbol{T} \cdot[\boldsymbol{u}]}{s_{c}\left(\Phi_{c}\right)} & \text { if } \boldsymbol{T} \cdot[\boldsymbol{u}] \geq 0 \\ 0 & \text { otherwise }\end{cases}
$$


This leads to:

$$
k_{c}\left(\varphi_{c}\right)=\sup _{\substack{\|\boldsymbol{T}\|=1 \\ \boldsymbol{T} \cdot[\boldsymbol{u}] \geq 0}}\left(\frac{(\boldsymbol{T} \cdot[\boldsymbol{u}])^{2}}{s_{c}\left(\Phi_{c}\right)}\right)
$$

Thus, for $[\boldsymbol{u}]=\left\{\begin{array}{c}\cos \varphi_{c} \\ \sin \varphi_{c}\end{array}\right\}$ and $\boldsymbol{T}=\left\{\begin{array}{c}\cos \Phi_{c} \\ \sin \Phi_{c}\end{array}\right\}$, we obtain:

$$
k_{c}\left(\varphi_{c}\right)=\sup _{\cos \left(\Phi_{c}-\varphi_{c}\right) \geq 0}\left(\frac{\cos ^{2}\left(\Phi_{c}-\varphi_{c}\right)}{s_{c}\left(\Phi_{c}\right)}\right)
$$

The condition $\cos \left(\Phi_{c}-\varphi_{c}\right) \geq 0$ implies, for a given $\varphi_{c}$, that:

$$
\Phi_{c} \in\left[\varphi_{c}-\frac{\pi}{2}, \varphi_{c}+\frac{\pi}{2}\right]
$$

The relation (21) becomes :

$$
k_{c}\left(\varphi_{c}\right)=\sup _{\Phi_{c} \in\left[\varphi_{c}-\frac{\pi}{2}, \varphi_{c}+\frac{\pi}{2}\right]}\left(\frac{\cos ^{2}\left(\Phi_{c}-\varphi_{c}\right)}{s_{c}\left(\Phi_{c}\right)}\right)
$$

The constitutive equations of the cracked section is obtained by differentiating $w([\boldsymbol{u}],[\boldsymbol{\theta}])$ as follows:

$$
\left\{\begin{array}{l}
T_{x}=\frac{\partial w([\boldsymbol{u}],[\boldsymbol{\theta}])}{\partial\left[u_{x}\right]}=\frac{\partial w_{c}([\boldsymbol{u}])}{\partial\left[u_{x}\right]}, T_{y}=\frac{\partial w([\boldsymbol{u}],[\boldsymbol{\theta}])}{\partial\left[u_{y}\right]}=\frac{\partial w_{c}([\boldsymbol{u}])}{\partial\left[u_{y}\right]} \\
M_{x}=\frac{\partial w([\boldsymbol{u}],[\boldsymbol{\theta}])}{\partial\left[\theta_{x}\right]}=\frac{\partial w_{f}([\boldsymbol{\theta}])}{\partial\left[\theta_{x}\right]}, M_{y}=\frac{\partial w([\boldsymbol{u}],[\boldsymbol{\theta}])}{\partial\left[\theta_{y}\right]}=\frac{\partial w_{f}([\boldsymbol{\theta}])}{\partial\left[\theta_{y}\right]}
\end{array}\right.
$$

Finally, the required relation is given by:

$$
\left(\begin{array}{c}
T_{x} \\
T_{y} \\
M_{x} \\
M_{y}
\end{array}\right)=\left(\begin{array}{cccc}
\frac{\mu \kappa S}{2 L} k_{c}\left(\varphi_{c}\right) & -\frac{\mu \kappa S}{4 L} k_{c}^{\prime}\left(\varphi_{c}\right) & 0 & 0 \\
\frac{\mu \kappa S}{4 L} k_{c}^{\prime}\left(\varphi_{c}\right) & \frac{\mu \kappa S}{2 L} k_{c}\left(\varphi_{c}\right) & 0 & 0 \\
0 & 0 & \frac{E I}{2 L} k(\varphi) & -\frac{E I}{4 L} k^{\prime}(\varphi) \\
0 & 0 & \frac{E I}{4 L} k^{\prime}(\varphi) & \frac{E I}{2 L} k(\varphi)
\end{array}\right)\left(\begin{array}{c}
{\left[u_{x}\right]} \\
{\left[u_{y}\right]} \\
{\left[\theta_{x}\right]} \\
{\left[\theta_{y}\right]}
\end{array}\right)
$$

\subsection{Identification of functions $s_{c}$ and $k_{c}$}

Three-dimensional finite element calculations were carried out under the Code_aster ${ }^{(}$ to identify $s_{c}$. The cracked structure, cf. Figure $4(\mathrm{a})$, is then subjected, at 
$z=2 L$, to the loading vector:

$\boldsymbol{F}=\left(T_{x}(2 L)=\cos \left(\Phi_{c}\right), T_{y}(2 L)=\sin \left(\Phi_{c}\right), M_{x}(2 L)=L T_{y}(2 L), M_{y}(2 L)=-L T_{x}(2 L)\right)$

which leads, at the cracked section $(z=L)$, to:

$$
(\boldsymbol{T}, \boldsymbol{M})=\left(T_{x}(L), T_{y}(L), M_{x}(L), M_{y}(L)\right)=\left(T_{x}(2 L), T_{y}(2 L), 0,0\right)
$$

Thus, the additional deformation energy due to the cracked section $w^{*}$ is reduced to $w_{c}^{*}$. The angle $\Phi_{c}$ varies in $\left[0^{\circ}, 360^{\circ}\right.$ at a rate of a loading case every

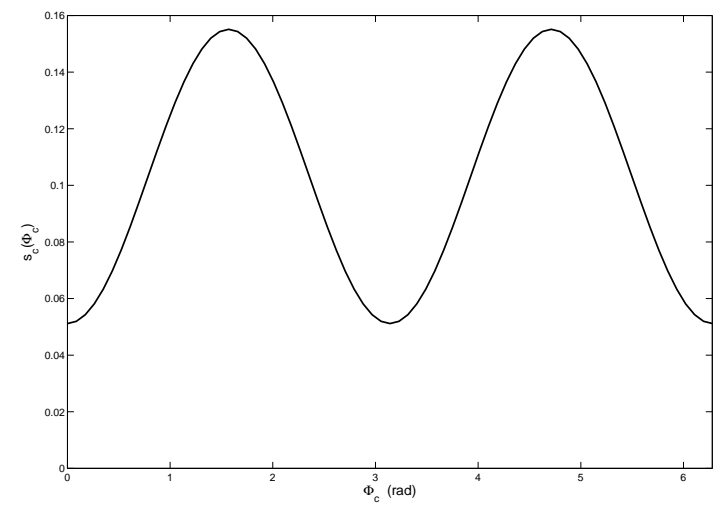

Fig. 5. Additional shearing flexibility $s_{c}, \frac{a}{D}=50 \%$

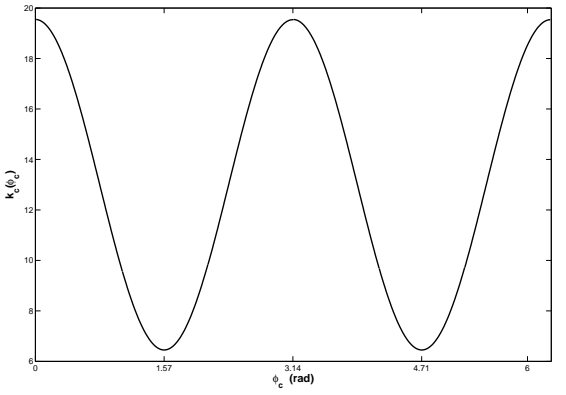

(a)

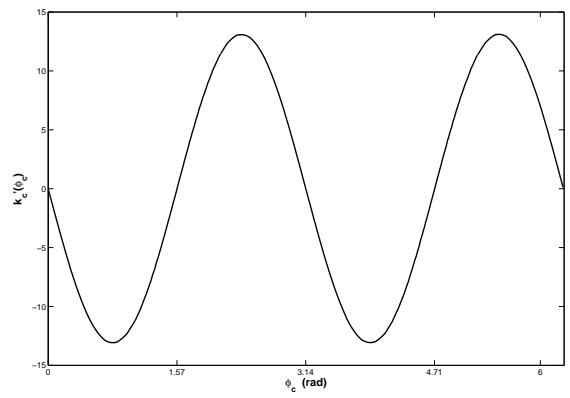

(b)

Fig. 6. Stiffness function $k_{c}$ and its derivative $k_{c}^{\prime}, \frac{a}{D}=50 \%$

$5^{\circ}$ and, thus, a total of 72 loading cases where carried out. The identification of function $s_{c}$ also requires the realization of the same three-dimensional calculations on the non-cracked structure (of the same geometry). The formula of Clapeyron makes it possible to calculate, for each loading case, the elastic energies $W_{s}^{*}$ and $W^{*}$ of the non-cracked and the cracked structures, respectively. Consequently, $w_{c}^{*}$ is given by

$$
w_{c}^{*}=W^{*}-W_{s}^{*}
$$


Since $\|\boldsymbol{T}\|=1$, and using the relation (11), the additional shearing flexibility function is obtained, for all loading cases, by:

$$
s_{c}\left(\Phi_{c}\right)=\mu \kappa S \frac{w_{c}^{*}(\boldsymbol{T})}{L}
$$

Figure 5 shows the evolution of $s_{c}$ for a straight line front crack with a relative depth $\frac{a}{D}=50 \%$. It is noticed in particular that $s_{c}$ does not vanish on $[0,2 \pi[$. Also, the strong dependency of $s_{c}$ on the loading direction $\Phi_{c}$ is clearly visible. Moreover, we show that the model presented by Varé and Andrieux [2005] corresponds to particular loading cases since

$$
s_{x}=\frac{2 L}{\mu \kappa S} s_{c}\left(\Phi_{c}=0\right), s_{y}=\frac{2 L}{\mu \kappa S} s_{c}\left(\Phi_{c}=\frac{\pi}{2}\right) \text { and } s_{x y}=\frac{2 L}{\mu \kappa S} s_{c}\left(\Phi_{c}=\frac{\pi}{4}\right)
$$

The stiffness function $k_{c}$ is then calculated by using the formula (22), cf. Figure 6(a). Finally, its derivative $k_{c}^{\prime}$ is calculated using the centered differences method, cf. Figure 6(b).

\subsection{Validation of the approach}

Now that we have identified the constitutive equations of the nodal element that represents the cracked transverse section, it is the objective of this section to introduce it in a one-dimensional FE code and see if we get sufficient agreement with three-dimensional representation. For a better validation of the approach, it is certainly more adequat to consider a cracked structure different from the one used in the identification procedure of the nodal element.

Let consider a cylinder of axis $(o z)$, diameter $D=0.5 \mathrm{~m}$, quadratic moment of inertia $I=\frac{\pi D^{4}}{64}$, total length $3 m$, clamped in $z=0$ and subjected at the other end to a couple of forces

$$
\mathbf{T}=\left(T_{x}=\cos (\alpha), T_{y}=\sin (\alpha)\right) \text { with } \alpha \in[0,2 \pi[
$$

The cylinder contains, at $z=1 \mathrm{~m}$, a straight line front crack with a relative depth $\frac{a}{D}=50 \%$. Three-dimensional calculations accounting for the unilateral contact without friction between the lips of the crack are carried using the code_aster $^{\complement}$. The one-dimensional model of the same structure is made of two non-cracked elements of Timoshenko beam type and respective lengths $1 \mathrm{~m}$ and $2 m$ connected at $z=1 m$ by a nodal element that represents the cracked section ( node 2), cf. Figure 7. Two cases are considered:

- in the first, the effects of shearing at the cracked section are neglected. Only discontinuities of rotations are then allowed at node $2\left(\left[u_{x}\right]=\left[u_{y}\right]=0\right)$. In this case we consider the model presented by Andrieux and Varé [2002]. 


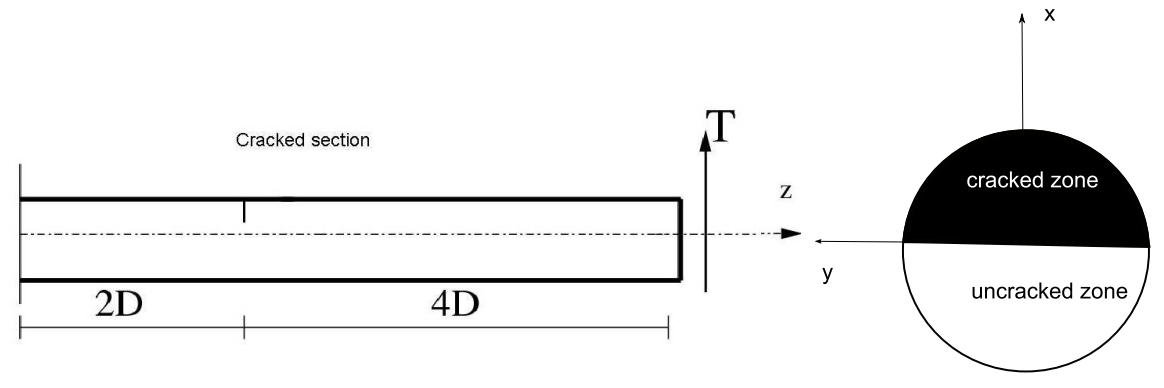

(a) 3D model

(b) Cracked transverse section

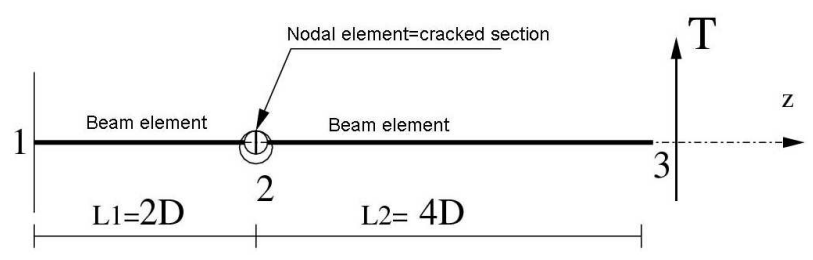

(c) Beam model

Fig. 7. Structure Modelling: $3 D$ and beam Finite elements
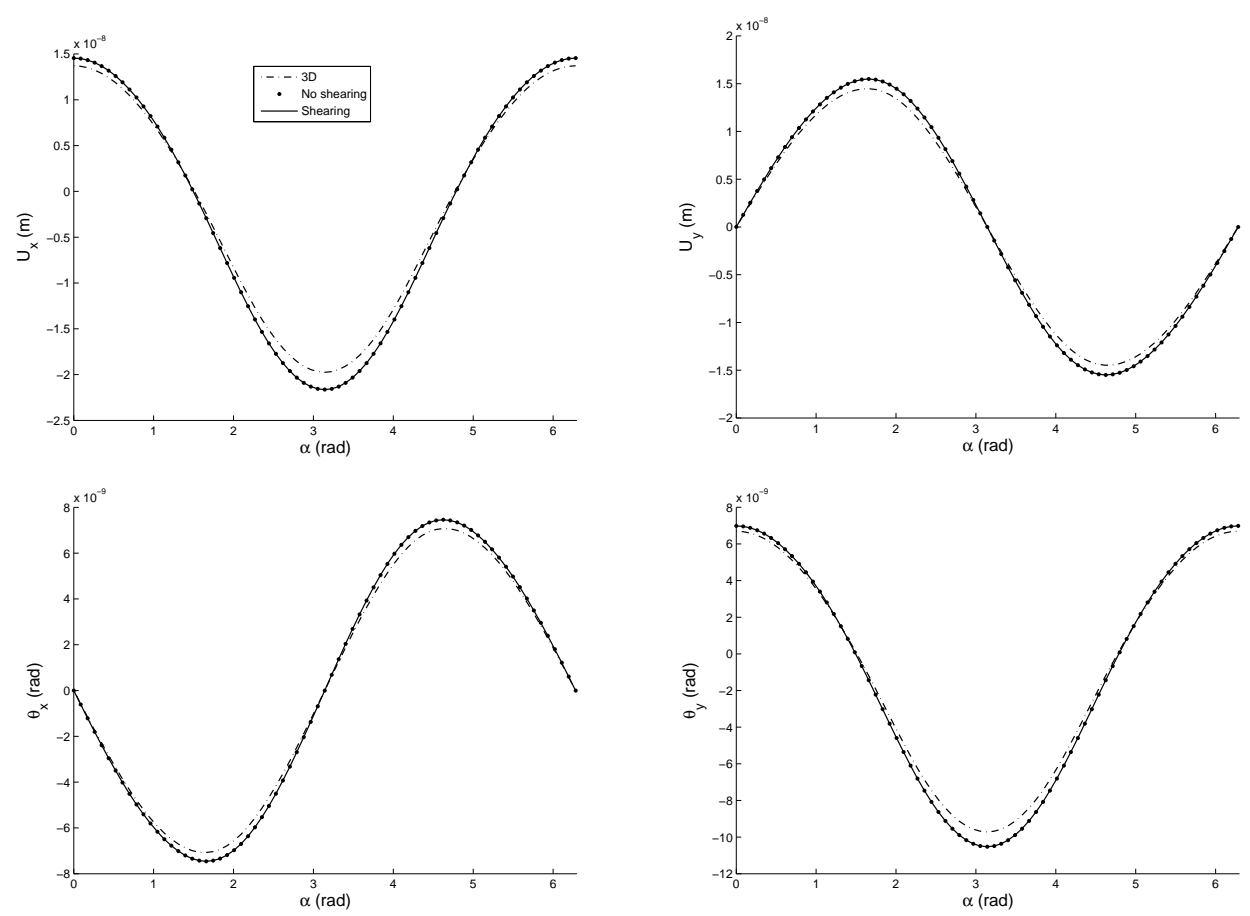

Fig. 8. Comparison of the present model to the three-dimensional results, $\frac{a}{D}=50 \%$.

- in the second, the nodal element behavior is described by relation (24): shearing effects are considered in this case.

Figure 8 shows an excellent agreement between the beam and the threedimensional models. It appears that the effects of shearing on the crack breath- 

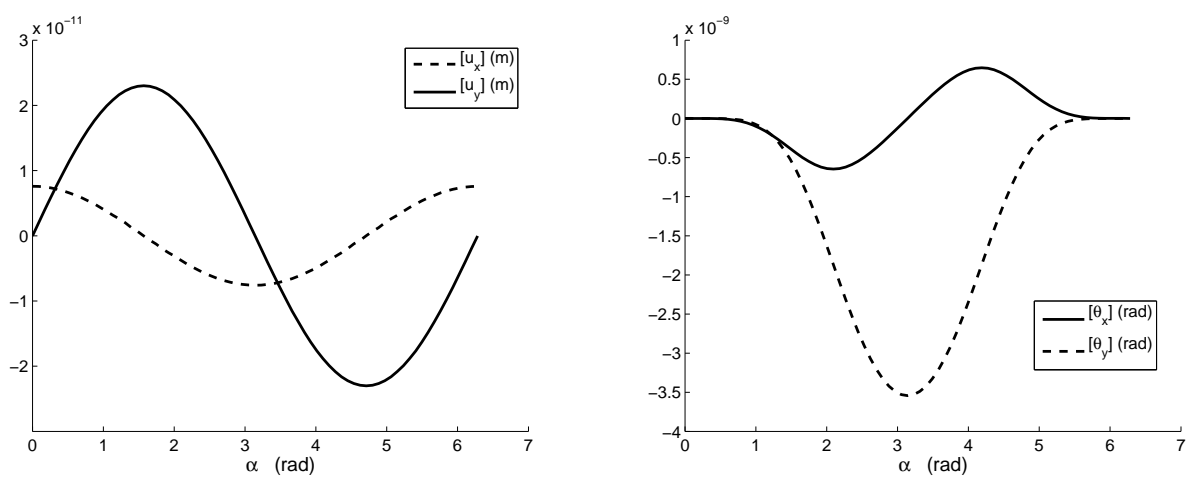

Fig. 9. discontinuties of the displacements and rotations at the cracked section, $\frac{a}{D}=50 \%$.

ing mechanism are negligible since the Andrieux and Varé [2002] model (with no consideration of the shearing effects) and the current model (taking into account the shearing effects) give the same results. The breathing mechanism is, thus, governed by the normal stresses on the crack lips.

\section{Conclusions}

The present approach consists in introducing the effects of shearing in the constitutive equations of a beam cracked transverse section. Three-dimensional calculations were carried out in order to identify the required nonlinear relations. In particular, the 3D nonlinear finite element calculations allowed the breathing mechanism of the crack to be predicted accurately. Based on the properties of the problem energy, the procedure presented in this paper could be applied to cracks of any shape and, moreover, to the case of multiple cracks affecting the same section. The approach was applied to the case of a single straight line front crack covering the half of a cylindrical beam cross section $\left(\frac{a}{D}=50 \%\right)$. For this form of crack, as illustrated in the Figure 8, the shearing effects on the breathing mechanism of the crack are negligible when compared to those of the flexural moments. The opening and closure of the crack are governed by the normal stress on the crack lips. The relative slip between the crack lips associated with shear forces remains very small compared to the rotations jumps due to the flexural moments at the cracked section (Figure $9)$.

Acknowledgements The author would like to thank Quoc-Son Nguyen and Habibou Maitournam (LMS, Ecole Polytechnique, France) for very helpful discussions. 


\section{References}

O. N. L. Abraham, J. A. Brandon, and A. M. Cohen. Remark on the determination of compliance coefficients at the crack section of a uniform beam with circular cross section. J. Sound Vib., 169(2):570-574, 1994.

S. Andrieux. Détermination de la loi de comportement en flexion bi-axée d'une poutre fissurée avec prise en compte du contact sur les fissures (in french). rapport interne HP-50/99/018/A, EDF-DER, 2000.

S. Andrieux and C. Varé. A 3d cracked beam model with unilateral contactapplication to rotors. European Journal of Mechanics, A/Solids, 21:793$810,2002$.

N. Anifantis and A. D. Dimarogonas. Identification of peripheral cracks in cylindrical shells. In ASME-Wint. Ann. Meet., Boston, Mass., USA, 1983.

H. F. Bueckner. The propagation of cracks and the energy of elastic deformation. Trans. ASME, 80:1225-1229, 1958.

Huy Duong Bui. Mécanique de la rupture fragile (in french). Masson, 1978.

A. D. Dimarogonas. A fuzzy logic neutral network structured expert system shell for diagnosis and prognosis- users manual. In EXPERTS, Clayton laboratories, St Louis, Missouri, USA, 1987.

A. D. Dimarogonas. Author's reply. J. Sound and Vibration, 169:575-576, 1994.

A. D. Dimarogonas. Vibration of cracked structures: A state of the art review. Engineering Fracture Mechanics, 55(5):831-857, 1996.

A. D. Dimarogonas. Dynamic response of cracked rotors. Internal report, General Electric Co., Schenectady NY, 1970.

A. D. Dimarogonas. Dynamics of cracked shafts. Internal report, General Electric Co., Schenectady NY, 1971.

A. D. Dimarogonas. Crack identification of in aircraft structures. In First National aircraft conf., Athens, 1982.

A. D. Dimarogonas. A general purpose rotor dynamic analysis program- users manual. In RODYNA, Clayton laboratories, St Louis, Missouri, USA, 1988.

A. D. Dimarogonas and S. A. Paipetis. Analytical methods in rotor dynamics. Applied science Publishers, 1983.

S. El Arem. Vibrations non-lineaires des structures fissurées: application aux rotors de turbines (in french). PhD thesis, Ecole Nationale des Ponts et Chaussées, 2006.

S. El Arem and H. Maitournam. Un élément fini de poutre fissurée: application la dynamique des arbres tournants (in french). European Journal of Computational Mechanics, 16(5):643-663, 2007.

S. El Arem and H. Maitournam. A cracked beam finite element for rotating shaft dynamics and stability analysis. Journal of Mechanics of Materials and Structures, 3(5):893-910, 2008.

S. El Arem, S. Andrieux, C. Varé, and P. Verrier. Loi de comportement en flexion d'une section de poutre fissurée avec prise en compte des effets de cisaillement (in french). In Gème colloque nationale en calcul des structures, 
volume II, pages 223-230, Giens, 2003.

R. D. Entwistle and B. J. Stone. Survey of the use of vibration methods in the assessment of component geometry. Vib. and Noise Meas. Pred. and Cont., Inst. engineers, Australia, 90:210-217, 1990.

R. Gasch. A survey of the dynamic behavior of a simple rotating shaft with a transverse crack. J. Sound and vibration, 160:313-332, 1993.

B. Gross and J. E. Srawley. Stress intensity factors for a single-edge-notch tension specimen by boundary collocation of a stress function. Tech. Note D-2395, NASA, 1964.

B. Gross and J. E. Srawley. Stress intensity factors for a single-edge-notch specimen in bending or combined bending and tension by boundary collocation of a stress function. Tech. Note D-2603, NASA, 1965.

P. Gudmundson. The dynamical behavior of slender structures with crosssectional cracks. J. Mech. Phys. Solids, 31:329-345, 1983.

G. R. Irwin. Analysis of stresses and strains near the end of a cracktraversing a plate. J. App. Mech., 24:361-364, 1957a.

G. R. Irwin. Relation of stresses near a crack to the crack extension force. In 9th Cong. App. Mech., Brussels, 1957b.

W. M. Ostachowicz and M. Krawwczuk. Coupled torsional and bending vibrations of a rotor with an open crack. Arch. App. Mech., 62:191-201, 1992.

T. Pafelias. Dynamic response of a cracked rotor. Technical Information Series DF-74-LS-79, General Electric Co., 1974.

C. A. Papadopoulos. Coupling of bending and torsional vibration of a cracked timoshenko beam. J. Sound and Vibration, 278:1205-1211, 2004.

C. A. Papadopoulos. The strain energy release approach for modeling cracks in rotors: A state of the art review. Mechanical Systems and Signal Processing, 22:763-789, 2008.

C. A. Papadopoulos and A. D. Dimarogonas. Coupled longitudinal and bending vibrations of a rotating shaft with an open crack. J. Sound vibration, 117:81-93, 1987a.

C. A. Papadopoulos and A. D. Dimarogonas. Coupling of bending and torsional vibration of a cracked timoshenko beam. Ing. Arch., 57:496-505, 1987b.

C. A. Papadopoulos and A. D. Dimarogonas. Stability of cracked rotors in the coupled vibration mode. In ASME-11th Bien. Conf. Mech. Vib. Noise, pages 25-34, Boston, Mass., USA, 1987c.

J. R. Rice and N. Levy. The part-through surface crack in an elastic plate. J. App. Mech., 39:185-194, 1972.

C.M. Stoisser and S Audebert. A comprehensive theoretical, numerical and experimental approach for crack detection in power plant rotating machinery. Mechanical Systems and Signal Processing, 22(4):818-844, 2008.

H. Tada, P. Paris, and G. Irwin. The stress analysis of cracks handbook. Del Research Corporation, Hellertown, pennsylvania, USA, 1973.

C. Varé. Calcul d'un modèle de rotor fissuré pour le code cadyro. rapport interne HP-54/99/047/B, EDF-R et D, 2000. 
C. Varé and S. Andrieux. Modeling of a cracked beam section under bending. In 18th International Conference on Structural Mechanics in Reactor Technology (SMiRT 18), pages 281-290, Beijing, China, 2005.

J. Wauer. On the dynamics of cracked rotors: A literature survey. Applied Mechanical Reviews, 43(1):13-17, 1990a.

J. Wauer. Modelling and formulation of equations of motion for cracked rotating shafts. Int. J. Solids Structures, 26(9):901-914, 1990b.

R. A. Westmann and W. H. Yang. Stress analysis of cracked rectangular beams. J. APP. Mech., 32:639-701, 1967. 